\title{
INSIGHTS AND ISSUES IN THE UPTAKE AND DEVELOPMENT OF ADVANCED ANAEROBIC DIGESTION WITHIN THE UK WATER INDUSTRY
}

\author{
ANDREW GOODING ${ }^{1} \&$ COLIN A. BOOTH ${ }^{2}$ \\ ${ }^{1}$ Wessex Water, UK \\ ${ }^{2}$ University of the West of England, UK
}

\begin{abstract}
This study explores the uptake and growth of Advanced Anaerobic Digestion (AAD) within the UK water industry to reveal the drivers and challenges the water companies are facing towards aiding the UK Government to reach its renewable energy targets. AAD was developed to replace anaerobic digestion $(\mathrm{AD})$ and increase cleaner biogas production and to decrease sludge volume and widen the application of bio-solids as fertilisers so that they can be used on all crops, therefore hugely decreasing waste sent to landfill. A mixed-methods approach of surveys and semi-structured interviews was targeted at the energy managers of each of the UKs water companies. Results reveal that industry professionals consider that AAD plays a key role within the water industry and significantly contributes to government targets regarding renewable energy production. The findings attest that government incentives do not promote future investment in AAD plants and water companies are investing for operational benefits. The current incentives advocate combining food and sewage waste in the construction of new food digestions plants, which is not only very costly, but also the construction of these plants has a large environmental impact, when existing systems could be utilised. The work highlights the main implications of investing into AAD and how the government incentives hindered the uptake from the water industry, therefore meaning a waste of potential energy that could have been harvested, which would have contributed to meeting the government targets.

Keywords: water companies, renewable energy, thermal hydrolysis, carbon footprint.
\end{abstract}

\section{INTRODUCTION}

Primary roles of the UK water industry are to provide clean drinking water for the nation and to remove and treat wastewater from domestic and commercial properties [1]. The industry was privatised in 1989 into twelve water companies [2]. Every five years, each of these companies has to present business plans (known as Asset Management Plans (AMP)) to the Water Services Regulation Authority (OFWAT). Based on the performance of each company in its previous AMP period, OFWAT determines the budgets for each of the companies in their next AMP period and also sets them targets to reduce customer bills and indicates where they want to see each of the company's focus their investments (e.g. sustainable energy or capital maintenance). Each company needs to detail how they plan to spend their entire allocated budgets, but also need to prove they are investing the tax payer's money into improving customer services and to insure the companies do not focus solely on making money for their stakeholders. The latest reports, regarding AMP-six plans (2015-2020), saw OFWAT [3] set strict targets about reducing the inflation of water prices that their customers pay, but also allow minimal expansion on current budgets. This poses the water companies with a difficult task over the coming years, as they look to save money, whilst also needing to make money.

This study explores the uptake and growth of AAD within the UK water industry, to reveal the drivers and challenges the water companies are facing towards aiding the UK Government to reach its renewable energy targets. 


\section{RENEWABLE ENERGY IN THE UK}

The UK Government is committed to meeting its target of using $15 \%$ of the nation's energy demand from renewable sources by 2020. The Department of Energy and Climate Change (DECC) [4] suggested that appropriate investment could be implemented to ensure progress in renewable energy. DECC [5] has outlined six areas that need to be tackled in order to extract the full potential of renewable energy: (i) facilitating access to the grid; (ii) ensuring long term investment certainty; (iii) tackling pre- and post- consent delays; (iv) ensuring sustainable bioenergy feedstock supply; (v) facilitating development of renewable supply chains; and (vi) encouraging innovation.

The Renewables Obligation [6] was established to drive the renewable energy target of 2020 by setting goals and penalties for electricity suppliers, but also incentives for companies producing electricity through renewable energy sources and feeding into the electricity grid. Electricity suppliers must produce a certain number of Renewables Obligation Certificates (ROCs) per year; otherwise they face financial penalties [7]. ROCs can be purchased from private companies that accrue them from the Office of Gas and Electricity Markets (OFGEM) [8]. For those water companies generating electricity through renewable energy, the ROCs received from OFGEM can then be sold to suppliers to gain financial benefit, as well as the generated electricity being sold to the grid for the current rate.

The Renewable Heat Incentive (RHI) was established for the commercial sector in 2012 [9]. The RHI is a UK Government scheme that creates financial incentives to encourage heat to be produced from renewable energy sources. Payments are made over a twenty-year period and are paid quarterly through submissions to OFGEM, with the amount paid determined by the type and amount of RHI produced [9]. This is part of the 2020 target for $12 \%$ of heating demand to be sourced from renewable energy.

The new RHI biogas tariff has shown minimal movement in regards to incentives paid, apart from bio-methane, which enables a good incentive for tier one of the payment plan. However, tier two and three have seen a significant reduction in price from the start of 2015. As a consequence, this does not incentivise large scale injection into the gas networks, as considerable work is required to turn biogas into bio-methane. A better return is offered by investing more into the electiricty market and obtaining ROCs.

\section{ADOPTION OF ADVANCED ANAEROBIC DIGESTION}

The UK's AD strategy and action plan for producing energy from waste was introduced in 2011 [10]. It is supported by the waste resource action programme, for increasing the use of $\mathrm{AD}$ to produce renewable energy, reduce landfill volumes and lower greenhouse gas emissions, whilst creating a fuel source from an unavoidable waste product. The action plan promotes how the method can be used to gain financial incentives, through ROCs, RHI and the Renewable Transport Fuel Obligation (RTFO) [10]. As a consequence, adoption of AD is making significant progress over its strategy and action plan, as there are 140 plants, which is 68 more than the baseline target and planning permission is agreed for a further 200 plants [11].

The water industry has been using $\mathrm{AD}$ to produce biogas for many years, along with other industries. The process of $\mathrm{AD}$ for sewage begins at the sewage treatment works, where solids and liquids are separated in a sludge bed (Fig. 1). The sludge is then contained in a digestion tank, where it degrades over time and gives off biogas, which can then be extracted and used for renewable energy [12]. Bio-solids are a waste product produced during this process (but is an efficient compost); however, UK law for agricultural use of 
human sewage states that strict testing of both bio-solids and soil is required, resulting in large quantities being sent to landfill [13].

The water industry has been investing and developing ADD. Unlike AD, it involves using pre-treatment methods. The only proven technologies are thermal hydrolysis, where solid sewage and sludge are heated to $140-170^{\circ} \mathrm{C}$, and enzymic hydrolysis, which occurs when pre-digested matter is heated between $40-60^{\circ} \mathrm{C}$ over a number of days and the $\mathrm{pH}$ reduced using enzymes [14].

Both methods mean pre-digestion matter can be digested quickly and more efficiently, creating more biogas. Research shows that thermal hydrolysis increases biogas production by $75-80 \%$ and enzymic hydrolysis by $30 \%$ compared to $\mathrm{AD}$ [15]. A study into thermal hydrolysis showed an increase in biogas production by $155 \%$ [16]. This process decreases the volume of bio-solids produced by $50 \%$ compared to $\mathrm{AD}$ and helps meet the standard for use as a fertiliser, meaning less is sent to landfill, reducing transportation costs and reducing the company's carbon footprint. Another advantage of using human sewage as fertilizer, is that it contains phosphorous, required in fertilizers for crops. Phosphorous is expected to start running low in thirty years, which could provide a renewable product. This would decrease the need of mining for phosphate, decreasing carbon emissions, as well as reducing the price, as the price has increased by $500 \%$ since 2007 [17].

AAD is compatible with all crop groups as a fertilizer, whereas conventional AD is not. This decreases the need for bio-solids to be disposed of, as it widens the number of users and AAD also reduces the volume of sludge by $\sim 50 \%$, so less bio-solids are produced compared to AD. Using bio-solids as fertilizers is the most sustainable option, as it reduces the need for artificial fertilizer [18]. Water UK [19] state $77 \%$ of sludge was used on land as fertilizer in 2013 , with $16 \%$ disposed through thermal destruction and $2 \%$ to landfill.

The biogas extracted after either thermal hydrolysis or enzymic hydrolysis can be burned in a combined heat and power (CHP) plant to produce heat and power, while the hot air that is generated moves a gas turbine, which creates electricity. The residual hot air can then be used to heat water, buildings, processes and it can be fed into a steam turbine to create more electricity or fed into the grid.

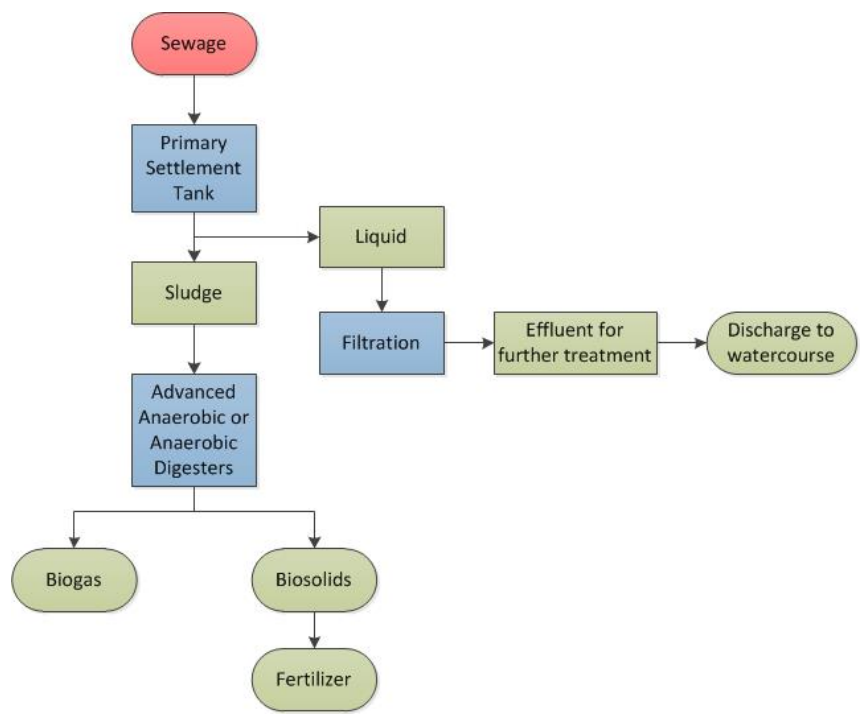

Figure 1: Sewage treatment process for $\mathrm{AD}$ and $\mathrm{AAD}$ sites. 
Another incentive put in place is the gas to grid for injection of bio-methane. In order for the biogas to be injected into the gas network, it must comply with strict quality controls. The biogas must be converted to biomethane, consisting of $98 \%$ methane and $1.5 \%$ nitrogen, with $0.5 \%$ made up of carbon-dioxide and hydrogen-sulphide [20]. Again, AAD is more advantageous than $\mathrm{AD}$, as it has higher methane content at approximately $60 \%$. In order to convert to bio-methane, bio-scrubbers and activated carbon filters are used to remove carbon-dioxide and hydrogen sulphide from the biogas and these processes produce odour free emissions [20]. Propane is then added to the methane, to comply with natural gas quality and the bio-methane can then be injected into the gas network to receive RHI payments.

Bio-methane produced from AAD now complies with compressed natural gas fuelled vehicles, providing the potential for expanding the use of bio-methane in transport. Not only would this reduce the use of fossil fuels, but also have environmental benefits, as a bio-methane vehicle reduces dangerous particulates by $97 \%$, and, thus, improves air quality. There is also an $80-90 \%$ reduction in nitrogen-oxides (NOx), which contribute to acid rain and city smog, and bio-methane produces $95 \%$ less carbon-dioxide than diesel. Even if the whole process is taken into account, from digestion tanks to use in the vehicle, it is still $\sim 30 \%$ reduction in carbon-dioxide over diesel. This proves that AAD in the water industry could branch out to provide renewable energy in other sectors. Fig. 2 provides an illustration of the different processes required for the renewable energy type, to produce heat, electric or bio-methane and it also shows how surplus can be redirected to aid other processes and avoid wastage of potential energy.

A disadvantage of these methods is the amount of energy required for pre-treatment heating, especially for higher temperatures needed in thermal hydrolysis. However, some of this heat can be recovered through the CHP, where the heat produced in the process can be

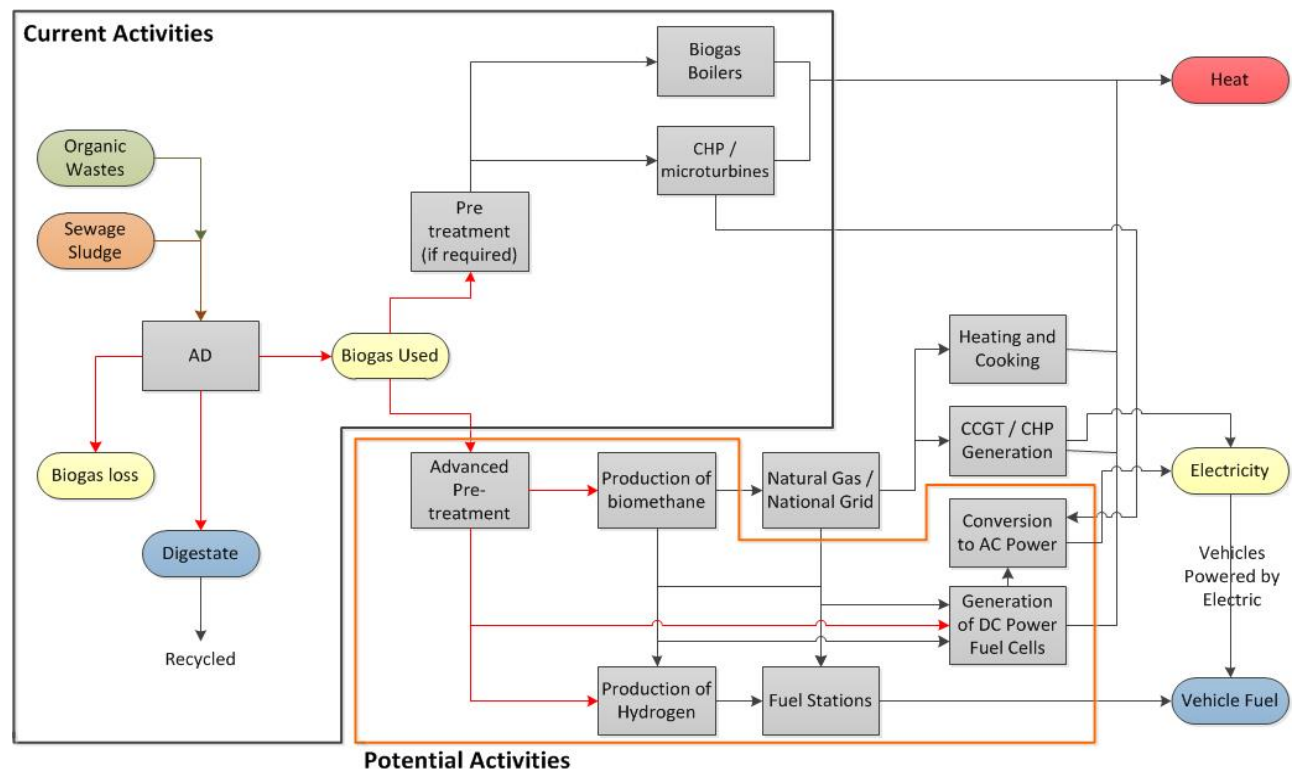

Figure 2: An illustration of how the biogas can be used [22]. 
recovered and used in the treatment process. Another disadvantage of thermal hydrolysis is that it increases the release of ammonia, creating an unpleasant smell, which causes odour issues for sewage treatment works in public areas [21]. Depending on how close the public live to the works, determines whether additional treatment is required to reduce odour levels. The Scottish Environment Protection Agency (SEPA) [21] explain that ammonia can also affect the bio-solid, because if ammonia levels are too high, the bio-solid will fail the fertilizer test as it can harm crops, and can have adverse effects on the environment if it enters the watercourse, such as being toxic to aquatic life.

\section{METHODS}

A mixed-methods approach was utilised to conduct the investigation. A questionnaire was sent to the renewable energy manager at each of the twelve water companies. The questionnaire comprised five sections: (i) the current renewable energy techniques used; (ii) how the companies are choosing to use biogas (e.g. heat, electric and gas); outputs the companies are achieving with AAD (e.g. carbon-dioxide reduction); (iii) capital outlay for AAD plants, as well as operational costs and payback periods; (iv) views on government incentives put in place for $\mathrm{AAD}$; and (v) future water company investment towards renewable energy and AAD. This provided twenty-four multiple choice questions, with options for participants to add comments. All participants were also invited to engage in semi-structured interviews addressing four overarching themes: (i) operational advantages and disadvantages of using $\mathrm{AAD}$ compared to $\mathrm{AD}$; (ii) preferred $\mathrm{AAD}$ process between thermal and enzymic hydrolysis; (iii) Government incentives to promote the uptake of AAD; (iv) performance of the network (including biogas quality and heat recirculation). At all stages of the investigation, the research adhered to the expectations and standards of the UWE ethics procedures and guidelines.

\section{FINDINGS}

All energy managers at each of the water companies returned their questionnaires $(n=12$; $100 \%$ response rate) and some agreed to be interviewed $(n=3)$.

\subsection{Survey findings}

Analysis of the survey data reveals that all the companies use hydroelectric and biomass as renewable energy sources $(n=12)$, and most of them also use solar power $(n=9)$ and wind turbines $(n=8)$. Ten companies currently use AAD on human sludge and, typically, these companies have between one and four AAD plants each. In regard to the use of AAD on food waste, none of the water companies are currently using this approach.

Ten of the twelve companies use the electricity they generate to power both their sites and to feed the grid; with just two companies producing for site only usage. This could be due to the size of the site, meaning there is no surplus to put in to the grid. All twelve companies use the heat generated from their CHP plants to heat and feed site processes, such as pre-heating sludge for the thermal hydrolysis. Only two companies use thermal properties to warm water and only three companies use it to heat buildings. This could be due to the amount of heat required for the AAD process, with there being minimal surplus for other applications. Nine of the twelve companies currently upgrade the biogas into biomethane and inject it back into the grid as part of the gas to grid scheme.

Reduction in carbon-dioxide from $\mathrm{AAD}$ to $\mathrm{AD}$ was not very complimenting, with five companies stating $<30,000$ tonnes in saving, with only two companies showing a reduction between 30,000 and 60,000 tonnes. This could be due to the number of AAD plants the 
companies have or the size of the plant. The lower amount of carbon-dioxide savings could be due to the energy required in the heating stage of sludge in AAD compared to no heating in an $\mathrm{AD}$ process. The ten companies that use $\mathrm{AAD}$, utilise $80-100 \%$ of the bio-solids produced for fertiliser, which avoids bio-solids being sent to landfill.

For the use of AAD in AMP-five (2010-2015), only eight companies proffered answers, with two companies using above 80 percent of its sludge in AAD, as seen by company ten who stated "100 percent after 2012, 60 percent before". Five of the eight companies answered that they use between $60-80 \%$ of their sludge in the AAD process, with two companies reporting less than twenty percent. Even when combining sludge used in AD and AAD for AMP-five, only five companies were using $>80 \%$ of their sludge between the two processes, showing that much potential energy is not being harvested. In AMP-six (2015-2020), the UK water companies plan to increase the amount of sludge being used in the AAD process. Five of the twelve companies will be processing $>90 \%$ of their sludge through AAD plants and four of them processing 70-90\% of their sludge in AAD plants.

The amount invested into AAD plants depends on the size and quantity of them. Some companies $(\mathrm{n}=3)$ claim to have invested between $£ 60-80$ million in AAD plants and several companies $(n=5)$ state $£ 20-40$ million of investment. The majority expect running costs between $£ 2-4$ million annually. Most companies who invest in AAD expect the process to payback its investment, either through operational savings or financial government incentives, within 5-10 years, and some expected the payback in $<5$ years.

Many of the companies believe government incentives do not promote future investment into AAD and that operational benefits outweigh the government's incentives. However, operational savings depend on the size of the AAD plant and that the larger the plant, the more economical they become. Half the companies state operational savings of $£ 2-4$ million, others seeing savings of $<£ 2$ million. The figures for ROC contributions were wide ranging ( $>£ 3$ million to $<£ 0.5$ million). This could be due to variations in the size or number of AAD plants; it could also be low if they are concentrating on bio-methane gas to grid scheme or if the company is using electricity primarily for site usage.

Companies within the water industry have future plans regarding renewable energy for AMP-six. Most of the companies $(n=9)$ are planning further investment in AD and AAD processes, with six companies expanding their solar and hydroelectric capacity, and four companies looking to expand their wind turbine projects. Of the nine companies investing in $\mathrm{AD}$ and $\mathrm{AAD}$, seven companies will be constructing new AAD plants in AMP-six, with five new sites confirmed and one company looking to expand their existing AAD plant. One company already has plans to build another two AAD plants in AMP-seven (20202025).

\subsection{Interview findings}

Interviews revealed the water companies prefer to use thermal hydrolysis, rather than enzymic, because of "massive performance differences" (Interviewee-A) between the two AAD processes. Furthermore, one company had trialled the two processes prior to investing in thermal hydrolysis and discovered data claims for enzymic hydrolysis were not accurate. They also found that thermal hydrolysis was far more efficient at killing pathogens and reducing volume.

The size of the plant and the volume needing to be processed was not considered a limiting factor in the choice of process, as the companies could build a plant to deal with any volume. However, another limiting factor identified for enzymic hydrolysis was that it fails to produce steam, whereas the steam created during thermal hydrolysis can be 
recovered to power a CHP plant to produce even more energy, or it can be re-circulated into the heating stage of the sludge, which reduces energy consumption.

The water companies who also manage food waste all use conventional AD. As there is no need for thermal treatment, $\mathrm{AAD}$ is not required with food because "there is no bursting of cells required" (Interviewees A, B and C), unlike sewage waste, which requires heat to burst cells. Installing an AAD plant will have no operational or financial benefits with food waste as "it will not reduce the digester size" (Interviewee A). The volume does not require thermal hydrolysis to help the process. AAD is a huge financial investment and requires high maintenance so there is no benefit to the companies to install AAD for food waste as the "current pasteurisers cope well" (Interviewee A).

In terms of incentives, all participants' attitudes were that nothing was likely to alter and any changes to improve the bio-solids assurance scheme have been suggested, which all water companies are signed into. They came up against barriers to prevent action regarding mixing industrial and domestic sludge into one process. Interviewee A stated that "government incentives were withdrawn very early into the development of AAD, from 2009 onwards, which slowed the development of AAD, it become a huge investment for very minimal return and was justified through operational benefit". The incentives were taken away far too early in the development stage of the process, which is when it was at its most expensive, prior to 2009 government incentives promoted AAD [23].

In terms of there being an optimal size for AAD plants, the responses were that operationally the larger the plant the better. This was not for any process reasons, such as being more economical or better heat recovery, but simply due to logistics, as it is cheaper and easier to have tankers travel further, than to build another AAD plant. Furthermore, it is also less of a capital investment, as it is cheaper to build one large plant than more smaller ones and also cheaper to maintain as it would require less AAD operators to run one large site than multiple sites.

From a financial investment view, due to the government incentives, there would be a better return from building small AAD plants. As smaller plants would not go over the upper level threshold for the amount of biogas produced and, therefore, would remain on the higher rate for financial return. However, due to high operational commitments and logistics, water companies use larger plants. The smaller plants attract private financial initiative partnerships that own and operate the plants, but pay to use the water company's asset so both make financial gains.

In terms of improvements to the current gas and electricity network, identified issues varied between each water company. Those with more urban divisions said there was minimal or no issue regarding current networks; whereas those with more rural areas indicated problems with accessing the grids. For instance, Interviewee A stated that their company had to install a two-kilometre pipeline in order to feed the gas back into the grid. Also, the quality of the gas is different from one area of the country to another. For instance, the North East have to comply with a higher calorific target, where the company is injecting $40 \%$ propane into the biogas product, in comparison to the South West area where the water companies are injecting $37 \%$ propane into the biogas, before injecting into the grid in order to meet standards.

There were no issues raised regarding electricity to the grid, as primarily the companies interviewed looked to recycle all their electricity for site usage, then the surplus is put back into the grid, which puts less stress on the current network. For future improvements, an interviewee said that there was a national body meeting held regarding gas to grid in the future, where they are looking at injecting just cleaned biogas straight into the grid and not adding propane to the product. There are no approximate dates for when this standard 
would be put in place. Interviewee A said that they think it is "many years away" but if this was to be put in place it would be a positive for water companies, as it would save them a process and subsequently decrease cost. Interviewee B said if this was put in place, it would be interesting to see how the gas to grid incentive would change, regarding the return price, as with removing a process and saving money it will be more than likely the return price will drop. This would still be an advantage, as less money will be spent by the company, meaning more money is left in their allocated AMP budgets to spend on other aspects.

In terms of the energy required during the heating of sludge in the AAD process, all interviewees said that sludge heating was not a major issue regarding energy usage, as the heat recovery systems in place are efficient and that the process was not a massive energy consumer. The methods used to keep the energy consumption down are recovering the steam released by the process and recirculating the heat into the stand-by boilers, and using the heat exchanger to pre-heat the sludge prior to the process. All the recovered heat is used in the 'front end' of the process where the sludge is dewatered more than the required water content. By using the standby boiler, hot water is added to the sludge to bring it up to $16 \%$ water content and doing this raises the temperature of the sludge and then the heat exchanger increases the temperature again, before the thermal hydrolysis begins. If the sludge was put straight into the process with cold $16 \%$ water content, it would require much more energy to heat the sludge.

There was a unanimous opinion by the interviewees that thermal hydrolysis requires far more maintenance than $\mathrm{AD}$. A highly trained operative is required to run $\mathrm{AAD}$ plants due to the extra issues that companies can face. Many inspections are required to ensure plants are working efficiently because heat and high working pressures of the plant place more stress on the equipment (e.g. valves breaking). The largest maintenance issue was the feed pumps, as grit causes stress and wear, leading to a significant reduction in performance. As a consequence, the plant requires shut downs to keep the optimal performance. Even though the plant requires this much maintenance, all interviewees perceive AAD to be superior to $\mathrm{AD}$ and is worth the operational issues, due to its volume reduction, consistency in results and ability to process at a much higher rate than $\mathrm{AD}$. With regards to the bio-solids, Interviewee-C stated that AAD produces a more consistent bio-solid that can be used as fertilizer on all crop types, whilst $\mathrm{AD}$ requires more treatment for it to comply to standards.

\section{CONCLUSIONS}

The largest issue for the continued uptake of AAD are the government incentives and policy. The main issues being that the incentives were dropped significantly in 2009 during a key stage in development, resulting in companies putting plans on hold, as it was an expensive investment with minimal or no financial help from the government, even though it was part of the AD plan to produce more energy from these sources. The government incentive put in place stated that sludge and food waste could be mixed, but the financial return would drop to the standard sludge rate of 0.5 rather than 2.0 for food waste, and there was no compromise for trying to utilise current plant. This resulted in water companies building separate food waste plants, as it was financially better in the long run. Building new plants comes at a high cost, approximately twenty million pounds, but also large construction has a negative effect on the environment for both carbon footprint and fossil fuel usage. The incentives put in place do not promote large scale AAD plants for financial returns but suggest installing smaller AAD plants, which is not viable for the water companies as operationally and logistically it would not work for them. From the interview, the participant had tried to propose ideas regarding the matter of mixing waste, but the 
government appeared to be uninterested and never responded, which does not promote a situation where everyone works together in order to achieve a better environmental result.

\section{RECOMMENDATIONS}

Recommendations drawn from this study are:

- The UK government needs to address the issue of mixing different wastes (such as food and sewage waste), as there is capacity to further utilise the AAD. The financial incentives put in place by the government do not encourage mixing and water companies are under the impression that the government are not promoting $\mathrm{AAD}$, causing them to believe that they should not mix waste to improve potential energy harvesting as they will not receive benefits.

- To put pressure on the UK government for biogas derived from AAD to be injected directly into the grid rather than being added to propane. This is at a very early stage regarding national body meetings, but the government and water companies need to put plans in place to bring this forward as soon as possible, as it will greatly benefit the water companies.

- The UK government needs to address incentives to promote water companies to start running their tankers on bio-methane produced at the AAD plants, as there is a lot of environmental gains to be had with running bio-methane, not only reducing fossil fuel usage but reducing the carbon footprint. The technology is already available and it is proven, but the right incentives need to be in place for it to be utilised. More research is required into the overall return in investment from $\mathrm{AAD}$ compared to $\mathrm{AD}$, especially when existing assets are involved.

\section{REFERENCES}

[1] Booth, C.A. \& Charlesworth, S.M., (eds) Water Resources in the Built Environment: Management Issues and Solutions, Wiley-Blackwells: Oxford, 2014.

[2] McEldowney, J., Water privatisation and regulation: the UK experience. Booth, C.A. \& Charlesworth, S.M., (eds) Water Resources in the Built Environment: Management Issues and Solutions, Wiley-Blackwells: Oxford, 2014.

[3] Water Services Regulation Authority (OFWAT), The Economic Regulator of the Water Sector in England and Wales, OFWAT: Birmingham, 2015.

[4] Department of Energy and Climate Change (DECC), UK Renewable Energy Roadmap, HM Government: London, 2011.

[5] Department of Energy and Climate Change (DECC), UK Renewable Energy Roadmap Update 2013, HM Government: London, 2013.

[6] HM Government, The Renewables Obligation (Amendment) Order 2014, The Stationary Office Ltd: Norwich, 2014.

[7] Department of Energy and Climate Change (DECC), 2010 to 2015 government policy: low carbon technologies, HM Government: London, 2015.

[8] Office of Gas and Electricity Markets (OFGEM), Information for Suppliers, HM Government: London, 2015.

[9] Office of Gas and Electricity Markets (OFGEM), Non-domestic Renewable Heat Incentive (RHI), HM Government: London, 2015.

[10] Department of Environment Food and Rural Affairs (DEFRA), Anaerobic Digestion Strategy and Action Plan: A Commitment to Increasing Energy from Waste Through Anaerobic Digestion, HM Government: London, 2011. 
[11] Department of Environment Food and Rural Affairs (DEFRA), Anaerobic Digestion Strategy and Action Plan, Annual Report 2014, HM Government: London, 2015.

[12] Waste Management World, Advanced anaerobic digestion: More gas from sewage sludge, 2015, Online. Accessed on: 3 Sep. 2015.

[13] Department of Environment Food and Rural Affairs (DEFRA), Managing Sewage Sludge, Slurry and Silage, HM Government: London, 2013.

[14] Bungay, S. \& Abdelwahab, M., Monsal Enzymic Hydrolysis - New Developments and Lessons Learnt, 2014, Online. Accessed on: 8 Sep. 2015.

[15] Phothilangka, K., Schoen, M.A. \& Wett, B., Benefits and Drawbacks of Thermal Pre-hydrolysis for Operational Performance of Wastewater Treatment Plants, Institute of Infrastructure: Austria, 2008.

[16] Miri, L., Abdoli, M. \& Mehrdadi, N., Effect of Thermal Hydrolysis on Anaerobic Digester Performance, Department of Environmental Engineering: Iran, 2015.

[17] Thames Water, Fertiliser from Sewage Saving the Planet and Cash, Thames Water: Reading, 2013.

[18] Water UK, Recycling of Biosolids to Agricultural Land, Water UK: London, 2010.

[19] Water UK, Biosolids Assurance Scheme: A Sustainable Solution, Water UK: London, 2013.

[20] Geneco, Gas to grid, Geneco Sustainable Solutions: Bristol, 2015.

[21] Scottish Environment Protection Agency (SEPA), Ammonia. SEPA: Glasgow, 2015.

[22] Newton, J. \& Chapman, K., Maximising the Value of Biogas, UK Water Industry Research: Leeds, 2012.

[23] HM Government, National Renewable Energy Action Plan for the United Kingdom. Article 4 of the Renewable Energy Directive 2009/28/EC, The Stationary Office Ltd: Norwich, 2009. 